Research Paper

\title{
SUSTAINABLE DEVELOPMENT FOR WATER RESOURCES OF LITOPENAEUS VANNAMEI PRAWN FARMING IN BAC LIEU PROVINCE
}

\author{
Huynh Phu ${ }^{1}$
}

\begin{abstract}
ARTICLE HISTORY
Received: February 08, 2020 Accepted: March 31, 2020

Publish on: April 25, 2020
\end{abstract}

\section{ABSTRACT}

Sustainable development for water resources of Litopenaeus vannamei prawn farming in Bac Lieu Province is a reciprocal relationship between 6 elements: Water - Shrimp Seed - Technology Engineering and Planning Management - Capital - Consumption Market. These factors are closely related to each other, ensuring a reasonable and stable development. Sustainable development of Litopenaeus vannamei prawn farming in Bac Lieu is firstly to protect the water source, maintain and protect other resources such as land, mangroves, aquatic resources, etc. The combination of protecting natural breeds with technical rearing nurseries is a decisive factor in the success of shrimp farming. The very important issue is that there should be an appropriate and sustainable economic plan, which means that the economic activity of Litopenaeus vannamei prawn farming in Bac Lieu coastal area must be profitable. In order to ensure that sustainability, it is necessary to have adequate investment capital, coastal people in general and in Bac Lieu in particular are supported by the State right from the stage of production preparation and consumption subsidy when necessary. With favorable geographical position, the issue of product consumption needs to be maintained and expanded in the market and needs to diversify shrimp exports to meet the domestic and for- eign social needs, in order to enhance income to be able to regenerate investment and protect the shrimp farming environment.

Keywords: Litopenaeus vannamei, Planning Management, Sustainable development, Water resources.

\section{Introduction}

Bac Lieu is located in the center of $\mathrm{Ca} \mathrm{Mau}$ Peninsula, with coordinates from $9^{\circ} 00^{\prime} 00^{\prime \prime}$ to $9^{\circ} 37^{\prime} 30^{\prime \prime}$ north latitude and from $105^{\circ} 15^{\prime} 00^{\prime \prime}$ to 105'52'30" east longitude. The North borders Hau Giang and Kien Giang provinces; East and Northeast borders on SocTrang province; West and Southwest borders Ca Mau province; East and Southeast borders the East Sea with a $56 \mathrm{~km}$ coastline. Bac Lieu is located in a tropical monsoon climate region with two distinct seasons: the rainy season from May to November, the dry season from December to April next year. The average annual rainfall is $2,000-2,300 \mathrm{~mm}$. The average temperature is $27.3^{\circ} \mathrm{C}$, the highest is $31.5^{\circ} \mathrm{C}$, the lowest is $22.5^{\circ} \mathrm{C}$. Number of sunny hours 2,500 - 2,600 hours/ year. The average humidity is $80 \%$ in the dry season and $85 \%$ in the rainy season (Nguyen, 2011).

Sustainable development of shrimp farming is a sustainable development for water resources. The policy of organizing aquaculture production, the orientation of the government of Vietnam is

$\triangle$ HUYNH PHU

Corresponding author: h.phu@hutech.edu.vn

${ }^{1}$ Ho Chi Minh City University of Technology 
to take the household economy, farm economy as the main form of production. The fact that shrimp farming has brought about high economic growth contributes greatly to poverty reduction for coastal people. The Prime Minister signed Decision No. 694/QĐ-TTg on May 24, 2017, establishing and promulgating the operation regulation of Bac Lieu high-tech shrimp farming zone. This is a great opportunity for Bac Lieu province to become the capital of industrial shrimp farming nationwide. Litopenaeus vannamei have replaced black tiger shrimp. Bac Lieu Province has more than 140,000 hectares for aquaculture, including 23,500 hectares for intensive and super intensive shrimp farming of which more than $80 \%$ are cultured Litopennaeus vannamei (ARDB, 2018). However, the longterm and stability issue are that the long-term planning should not be sudden, causing instability in the shrimp farming industry. This research attempt to study and evaluate water quality in Litopenaeus vannamei farming area of Bac Lieu Province and propose water treatment solution for Litopenaeus vannamei farming for sustainable development.

\section{Research methods}

Selectively and systematize relevant research results: collect documents on natural conditions (temperature, humidity, rain, hydrology, forest, soil, etc). The document on water quality environment has been integrated into previous Litopenaeus vannamei farming projects.

Methods of survey and measurement: Arranging measurement in the experimental ponds (static state). Arranging measurement based on the rainy season, dry season, ebb and flow (dynamic state) in the context of complicated weather conditions. The study was conducted on a large scale to collect data as a basis for fully assessing the environmental status of the water area of the study area.

Method of rapid environmental assessment: Use materials that have calculated pollution levels quickly to determine the impact of Litopenaeus vannamei farming on water quality.

Methods of statistical analysis: Using statistical analysis and processing of monitoring data to establish the correlation between water quality factors.

Systematic analysis method: The water resources in the study area are influenced by many interrelated factors such as climate, soil, mangroves, hydrological regime, etc and the activities of people involved in Litopenaeus vannamei farming. When analyzing changes in water quality environment, it is necessary to consider from a systematic point of view to evaluate the interaction between water quality environment factors.

\section{Results and discussion}

\subsection{Development}

\section{Water source}

Rivers in Bac Lieu Province are an integral part of the $\mathrm{Ca}$ Mau Peninsula river system and are influenced by tides from the East and West Sea.

\section{a) Tide}

Bac Lieu Province is influenced by the East Sea and West Sea tides. East Sea tide is semi-irregular irregular tide, there are 02 peaks and 02 feet in the day, there are two high tide and two low tide periods in a month. During the year, the high tide peaks in December-January and low in June-July, the difference is $0.5 \mathrm{~m}$. The East Sea tide has a high tidal range of $3.0-3.5 \mathrm{~m}$ during high tide and from $1.8-2.0 \mathrm{~m}$ during ebb tide. The tide level fluctuates greatly (1.6-3.0m), while the tidal water level fluctuates smaller $(0.8-1.0 \mathrm{~m})$ thus limiting the ability to drain but is more convenient for Self-flowing irrigation (Nguyen, 
2003).

The West Sea tide belongs to a mixed tide, favoring diurnal tide. The times of ebb and flow are approximately the same, usually lasting from 11.3-12.0 hours. The largest tidal range varies from $0.8-1.2 \mathrm{~m}$. An average tide period of 15 days, during the year, the highest monthly average occurs in November-December, the lowest occurs in April-V, coinciding with the lowest water level in the Hau River. The West Sea Tide has a low tidal range $(0.2-0.4 \mathrm{~m})$, while tidal peaks fluctuate more $(0.6-0.8 \mathrm{~m})$, making it difficult to use tidal peaks. Irrigation water flows but it is more convenient for drainage.

\section{b) Surface water}

Flow generated from tidal energy. Factors affecting flow hydrography include: Hau river flow regime, East and West sea tidal regime, rainfall regime, regulation of irrigation works system, production structure agriculture, basin topography. The regime of the East Sea has the greatest influence on all areas and at all times. Because the river is far from Hau river and the hydraulic slope between the two ends of the water is quite small, especially in the dry season, the flow of fresh water on the Quan-Phung Hiep canal has low flow. From January to April, the tidal current is absolutely dominant, sometimes saline water passes over Ninh Quoi crossroads. Flow in the canal system has a lot of water borders, which is detrimental to water supply and drainage.

Fresh water source in irrigation areas, Bac Lieu has 3 main sources of fresh water including the fresh water source is taken from Hau River with limited capacity in both supply flow and the period to be met, rainwater, the main source for agriculture, and fresh water sources for groundwater. This situation also puts the province's agriculture in a precarious position, much dependent on the annual climate change. Salt water is also an important source in the province's aquaculture and salt production. This is an advantage of a coastal province (Huynh, 2019).

\section{c) Water quality}

There are two distinct areas which the fresh water all year round corresponding to the agricultural production area and the salt water area corresponding to the aquaculture area. Freshwater areas in general have good water quality to meet the needs of freshwater seedling development. However, this ability is only evident in the rainy season. At the beginning of the rainy season, the alum wash water from the fields into the rivers and canals is concentrated. In the dry season, water shortage cannot open more rice crops; drought "grandmother" in the rainy season also made the water alum again. The ability to receive fresh water from Hau river through Quan Lo Phung Hiep canal is not high because the distance is too long, the water level in the Hau river drops too low. The expansion of agricultural production in the dry season causes a high demand for water, the lower water level of Quan LoPhung Hiep canal, creating conditions for deep saline intrusion, crossing the Bac Lieu-Soc Trang boundary. Wastewater from agricultural production areas spread on canals is also a factor to narrow the time and period of taking salt water for aquaculture. Quan Lo-Phung Hiep canal is both a source of fresh water and a major source of salt water for the northern transition area of National Highway 1A, and is also a main waterway with a technical grade of grade III. Salinity - sweetness over time depends on the operation of the sluice, many times of the year cannot simultaneously meet the benefits of all rice and shrimp production areas. Basically, the water in rivers and canals is always sequentially transformed according to the following states in the annual cycle: Salty $=>$ brackish $=>$ brackish sour $=>$ sweet $=>$ brackish $=>$ salty (Huynh, 2019).

Water is an economically valuable resource 
and in use must attach importance to the economic value of water resources. The mode of culture, and especially the water supply and drainage system for the shrimp farming area, is of great importance in minimizing the negative impact on the environment, the overload of nutrition, the overload of waste causing shrimp diseases. In addition, a very important factor in the choice of farming methods is associated with the financial capacity of the farmers to ensure the economic and social benefits for the people and the community in the region. Semi-intensive farming is an area-saving culture that can prevent disease and waste problems in intensive culture. Extensive shrimp farming is mainly based on nature, which has few direct negative consequences on the water quality environment. But due to extensive shrimp farming has reduced the resources of wild shrimp, which is the result of mangrove deforestation, the maximum exploitation of natural shrimp flocks, coastal water resources have been reduced polluted.

\section{Shrimp Seen}

Shrimp farming in Bac Lieu is currently preferred because intensive and semi-intensive farming, local varieties do not meet the needs of farming in the province but also have to import seeds from neighboring provinces or must bring from the central region. Hatcheries are struggling because of a virus infection from wild shrimp and pollution caused by hatchery itself. Therefore, it is necessary to take proactive measures for seeds, ensuring good adaptation to the natural conditions in the region (Tran, 2009).

Technology Engineering - Irrigation - Environment

Irrigation for shrimp farming is the work of water supply and drainage, a dike system to protect shrimp farming areas. Common irrigation systems of grades I and II require the State to invest in infrastructure for people, while in-field canals lead water into ponds built by people ac- cording to planning (Huynh, 2019). Water supply option with gravity and pump needed. Once a pond has reached the technical requirements, ensuring good water supply and drainage for shrimp, the care of Litopenaeus vannamei farming plays an essential role. The first basic requirement in Litopenaeus vannamei farming is good water quality, monitoring of physical and chemical parameters is very important, to monitor fish physical and chemical indicators every day Monitoring clarity, $\mathrm{pH}$, pond water temperature farming...), and periodically monitor salinity and algae in the pond (Huynh, 2019).

Proper management and treatment of wastewater and waste from shrimp culture will reduce the impacts on the water environment. Experience from countries in Asean, Thailand, Malaysia and in China has shown that shrimp diseases such as The Yellow Head Virus (YDV) and White Spot Syndrome Virus (WSSV) only have the problem with active prevention is in water management and the use of a low water exchange model (Boy, 1998).

The negative impacts on the water quality environment due to Litopenaeus vannamei farming activities not only in our country but also in many countries in the world are also facing with waste water and waste from Litopenaeus vannamei ponds. In Thailand, Indonesia, they are facing obstacles due to the water supply for the ponds which is not of good quality for Litopenaeus vannamei farming due to wastewater from processing industries and the aquaculture industry itself. In our country due to the low level of industrial waste discharged into coastal areas, the main task is to monitor and treat waste water and waste from Litopenaeus vannamei farming.

Currently many new techniques are applied in the treatment of waste from shrimp ponds. But an effective solution to prevention rather than cure' is to encourage the use of shrimp feeds of clear origin and strict testing to minimize organic 
waste into the environment management and improvement of the pond environment, it is necessary to strictly abide by the following technical measures: building irrigation water supply and drainage systems for the complete Litopenaeus vannamei farming region; before each crop must remove the bottom of the pond and remove the mud layer from the rearing area, treating the substrate with Chlorine and lime; ponds must have settling ponds and treat them before putting them into ponds; fertilizing water color for the pond; Using the seed through quarantine, to select the seed without pathogens; it is recommended to use industrial food; home-made fresh food must be cooked to avoid polluting the water environment.

\subsection{Sustainable}

\section{Zoning}

It is necessary to have a system for directing fisheries management from the provincial level down to the rearing areas according to the farm or cooperative scale. Regularly ensuring logistics for farming areas, feeds, medicines and guiding the dissemination of basic knowledge about Litopenaeus vannamei farming models to farmers in order to develop shrimp farms with high economic efficiency. Proper and rational planning is a key step for the sustainable development of coastal shrimp farming. The plan is elaborated in detail, specifically with full consideration of economic - environmental - social factors, not just land, infrastructure. Litopenaeus vannamei farming planning is associated with the general development plan of the province and it is especially necessary to limit the level of development and expansion of the area. The development of Litopenaeus vannamei farming must be synchronized with investment in irrigation systems and technical infrastructure along the direction of "working together with the people and the people". The development of coastal Litopenaeus vannamei farming must go hand in hand with environmental protection, natural resources protection and public health.

\section{Capital}

Capital is always a pressing issue for the shrimp farming work of coastal people. Funds for investment in irrigation systems, loans for people in the early stages to buy breeds, build embankments, improve land and product development costs. The amount of capital invested by the State is prone to change and usually decreases compared to the initial estimate. The government should have policies to support coastal people in Litopenaeus vannamei farming and they are protected for seed capital and initial investment. Especially, the State should put capital sources for coastal aquaculture into the annual fiscal year of the State. Appropriate tax and credit policies are needed to encourage stable shrimp farming. At the same time, to organize the association of Litopenaeus vannamei farmers and shrimp processors from the local to the central level and adopt protection and subsidy policies when necessary to protect the interests of farmers as well as deal with price fluctuations shrimp on the World market.

\section{Consume}

The final step that determines the success or failure of the sustainable development of Litopenaeus vannamei farming. Output - Processing Consumption. Processing to create the final product in the food chain. Depending on the market, there are different processed products. Building shrimp processing factories to serve the diversification of products from shrimps and factories supplying clean water for processing, in order to meet the demands of clean food for export. Strengthening the development of export markets, developing the domestic market, meeting the needs of increasing the food needs of the people.

\section{Water resources sustainability}

The water source is not over-exploited and 
naturally replenished. The requirement of this criterion is that the water supply must not only be stable, ensure both the quantity and duration of water supply, but also the requirement that the water source must not be over-exploited. There are two issues that need to be addressed: Managing water resources appropriately to avoid conflicts between water user groups and ensuring the environmental sustainability of water.

Currently, the management of water resources in most developing countries as well as in our country has not had a close coordination between the three components, especially water users have little opportunity to participate in management Water source. The planners and policymakers have not had close cooperation with each other yet.

\section{Sustainable irrigation construction works}

Water supply requirements for the ponds should be calculated not only for the amount of washing water, first supply, additional supply, periodic drainage, rainwater drainage, emergency discharge, harvest discharge but also calculated hydraulically via network problems. Therefore, it is necessary to choose hydraulic diagram, boundary conditions, design frequency, solution, work arrangement, it is related to the calculation results.

According to the principle of equilibrium, the total amount of water needed for shrimp farming process is calculated by the following Equation (1).

$$
\begin{aligned}
\mathrm{W}_{\text {Demand }}=\mathrm{W}_{\text {washed at the beginning of crop }}+\mathrm{W}_{\text {stability }}+ \\
\mathrm{W}_{\text {replacement }}+\mathrm{W}_{\text {additional }}
\end{aligned}
$$

where $\mathrm{W}_{\text {washed at the beginning of crop }}$ is the supplementing pond water due to leakage a quantity of water is needed to wash the pond at the beginning of the season, in case a new pond is built, the amount of washed water put into ponds with a water level of $>0.5 \mathrm{~m}$, in case of rearing ponds have passed a few crops with the water level of only $0.4 \mathrm{~m}$ and the period of submerging the pond for one week; $\mathrm{W}_{\text {stability }}$ is the shrimp ponds after completion of the preparatory work, taking water to raise the water level to $0.8-1 \mathrm{~m}$. After stocking the animals, in the first month, raise the pond water level to $1.2-1.5 \mathrm{~m}$ and from the $3 \mathrm{rd}$ month onwards, keep it stable at $1.5 \mathrm{~m}$; $\mathrm{W}_{\text {additional }}$ is the addition water to the pond due to leakage losses, due to heat, rising water temperature and salinity to promptly supplement to stabilize the temperature and salinity of the pond. The amount of water added each time does not exceed 15\%o of the volume of pond water. When salinity exceeds $30 \%$ fresh water should be added to reduce salinity to below $30 \%$; $\mathrm{W}_{\text {replacement }}$ is the amount of water exchanged during the shrimp culture process is because the water quality in the pond is not consistent with the water quality requirement of the shrimp. If shrimp are diseased or hard to molt, they need to replace pond bottom water with stored and treated water. The amount of replacement water should not exceed $15 \%$ and must be changed many times according to the tide (Huynh, 2019).

Exploiting and using the water quality environment in the shrimp farming process ensures the best use of water sources and contributes to mitigating water environment fluctuations. Criteria for evaluating irrigation systems must not only require works to be well-functioning, provide enough water but also must ensure the standards prescribed for water quality required by the fishery industry. To monitor the quality of water during operation, there must be a regulation on water quality testing. There are two types of inspection: regular and periodic inspection (specified in the water quality standard for the number of indicators to be monitored) and abnormal testing when there are certain uncertainties about the quality water by sensory or by abnormal climatic weather. Now, inter-sectoral organizations Irrigation - Fisheries - Environ- 
ment find the issue of water supply, drainage and sanitation in areas planned for shrimp farming very important. But sustainable development of water supply and drainage systems, ensuring the best water supply for shrimp farming is still a great challenge.

The second issue that needs to be considered is financing with identifying the financing provided to the right object and the right purpose. There must be clear delineation and agreement among the stakeholders, making people understand their rights and responsibilities for what they enjoy with a comfortable attitude. However, it is also necessary to explore the ability of people's investment to adequately allocate costs. At the national and regional level, it is necessary to take into account inflation, income stabilization and employment of the people and have the right policy for providing finance for survival and development.

The third issue is to build a skilled technical team to manage and monitor Litopenaeus vannamei farming. The organization of staff training is lacking, the qualifications of staff are low. Need to clarify the responsibilities, management roles and roles of the parties involved. Draft and use the shrimp manual. Training skilled workers in service of aquaculture are necessary.

The fourth issue is policies and legal documents. Clear and coherent laws and regulations are required to: a) Clarify responsibilities between localities and households involved in farming; b) Procedures for selecting varieties and selecting technologies; c) The role of the private sector to participate; d) Cost offset policy; e) State role in management, including supporting role.

Reasons to promote community participation

Promoting community participation involves: a) with community involvement a lot of work is completed, b) with the participation of the community, the services are distributed cheaper, c) this participation has practical benefits for the participant, d) this participation is a catalyst for strong growth, e) This participation promotes a sense of responsibility, f) this participation helps us realize whether there is a need, g) This participation ensures that all work is done, $h$ ) this participation frees people from their dependence on others, i) this engagement makes people better understand the causes of poverty and how they can fight poverty.

Participation of private sector and community management

In the context of crop transformation and strong government policies that allow for an increase in shrimp farming area, private sector participation is seen as a more efficient and economical way of doing business for enhancing production capacity. Private sector involvement includes small contractors and privatization of public services. The purpose of involving the private sector and the management community is to reduce burdens on State agencies and to ensure sustainable water supply. Community management does not mean that any project that the community owns and manages, they must take care of all issues. Communities are allowed to invite private participation, either to sign contracts to operate or to hand over the whole project to the contractor for management. The problem is that the community has the right to choose who to sign a contract for as long as possible. Usually, centralized water supply management is undertaken jointly by community and private organizations and groups.

Responsibilities of the Management Board in the community

Responsibilities of the Management Board in the community includes showing the relationship between the community and the management agency, organizing community contributions in cash or any other form of construction, operation and maintenance, including custodian supervi- 
sion, storing financial data, improving the efficient use and protection of new water supply facilities, organizing regular meetings to discuss and decide on procedural issues, notifying the community on a regular basis about decisions and monitoring reports of expenditures. When community measures are taken and the construction works are closely involved in the planning, care must be taken to transfer the long-term responsibility for the project management to the community until the construction completed. In fact, in many cases the community has little or no participation in the project planning process.

\subsection{Sustainable development for Litope- naeus vannamei prawn farming}

In 2019, the situation of high-tech for Litopenaeus vannamei farming in Bac Lieu will be very satisfactory, with an area of 1,000 ha and an output of 19,082 tons. Like some coastal provinces in the Mekong Delta, Bac Lieu has the advantage of being a land of salt and brackish water, with a total area of shrimp farming of more than 136 thousand hectares, of which 22,000 hectares are modeled. Intensive, semi-intensive and more than 1000 ha rearing under the ultra-intensive model in closed houses with high technology application, can yield from 120 to 150 tons/ha per year.

With the above advantages, Bac Lieu Province has identified shrimp as a key area of the province, according to which the province has focused on infrastructure investment and the development of the whole system chain, from seed production, materials to shrimp industry, developing models of high-tech for Litopenaeus vannamei farming and export processing. In 2019, Bac Lieu seafood industry has made remarkable progress (the output exceeded 5,000 tons of shrimp compared to the plan). The Agriculture sector has focused on active, drastic and effective implementation, with a focus on developing for Litopenaeus vannamei farming, focusing on high-tech agriculture zone, making Bac
Lieu a center of shrimp industry nationwide. Although there are still some difficulties for shrimp farming such as large initial investment capital, the price of inputs (breeds, feed, aquatic drugs) always fluctuates in an increasing trend, the situation of epidemics. On the shrimp, the situation is quite complicated while the output price is not stable. At the end of 2019, the situation of superintensive for Litopenaeus vannamei farming, high technology achieved very satisfactory results, the farming area was 1,000 hectares $(2.5$ times more than the plan), the output reached 19,082 tons (nearly doubled plan).

One of the current effective shrimp farming models in Bac Lieu is the super-intensive for Litopenaeus vannamei farming model with 2 periods of low water exchange. The first period of Litopenaeus vannamei farming is in a 20-30 days net house to avoid the impact of weather and other external factors. When shrimp has a weight of $0.5-1.5 \mathrm{~g} / \mathrm{head}$, move to stage 2 in the adjacent pond. At this pond, shrimp are cultured at a density of 150-250 shrimp/m2, cultured until they reach the size of $50-30$ shrimp $/ \mathrm{kg}$. Total farming time is 80 - 100 days. A special feature of this farming process is that they do not use chemicals, only use probiotics.

According to the preliminary assessment of the industry, some businesses and households implement the effective high-tech shrimp farming model. In case of lined ponds, the average is 50 tons/ha of water surface/crop (the highest is 77 tons/ha/crop, the lowest is 25 tons/ha/crop), for round ponds, the average is 60 tons/ha of water surface/crop (the highest is 70 tons/ha/crop, the lowest is 50 tons/ha/crop). In order to sustainably develop for Litopenaeus vannamei farming in Bac Lieu Province, investment in infrastructure of farming areas as well as application of scientific and technological advances are to turn the province into a capital city shrimp industry of the whole country. 


\subsection{Solutions to water resources treatment and pollution minimize}

Table 1. Influencing factors and solutions to mitigate and protect water sources

No. Factors affecting water quality $\begin{gathered}\text { Solution to remove } \\ \text { minimize water protection }\end{gathered}$

1 When the water circulation is poor, the pond bottom is not treated well before stocking shrimp. Proposed water quality for Litopenaeus vannamei prawn farming: $\mathrm{T}^{\mathrm{o}}$ : 22-32; Salinity: 6$15 \%$; pH: 7 - 9; DO: 4 - 9 mg/l; BOD < 10 $\mathrm{mg} / \mathrm{l}$.

2 Tidal impacts on water supply and drainage for shrimp ponds. The existing shrimp ponds have only one water supply and drainage pipeline, the water is discharged in a vicious way and then resupplied, making shrimp ponds often have to supply contaminated water.

3 When the content of suspended solids increases, in anaerobic conditions, the content of Nitrate and Phosphates affects shrimp life.

$4 \quad$ Shrimp feeds, especially those made by the people themselves, are derived from mollusks, when the excess in the pond causes stench and the water is very polluted.

5 Chemical pollution due to the use of pesticides for agriculture has gradually lost the natural food for fisheries.

6 Biochemical pollution, the process of synthesizing toxic and non-toxic substances synthesized inside the shrimp body to create a highly toxic compound

7 Biological pollution is very harmful but hard to see, the import of breeding animals from one region to another. Bringing the seed in the polluted water to another farming area. Breeding and rearing animals, in the absence of basic knowledge, causes pollution in the aquatic system, there are risks of disease outbreaks.

8 Ecological pollution: The ecological pollution in estuarine and coastal areas is caused by human beings actively disrupting the ecology. The exploitation and selection of species have accidentally increased the variety and polluted ecosystems.
Ponds must be properly treated and fertilized with lime and other fertilizers, creating good colors before stocking shrimp. Pond mud is removed and dried for more than 2 weeks before stocking shrimp

Ponds need to be arranged separately for water supply and drainage. Before supplying water to the pond, a pond is required to store water to settle, to meet the required criteria for Giant tiger prawn culture before supplying water.

Salinity, $\mathrm{pH}$ and dissolved oxygen tend to increase from inland to the sea. The concentration of suspended substance tends to decrease gradually from inland to the sea. Shrimp ponds must be large enough. Food must be in the right dosage, avoid excess, causing water to stink, waste must be managed and buried in accordance with regulations.

Manage the supply of pesticides, plan appropriate zoning. It is necessary to build a construction system to separate agricultural production areas from aquaculture areas.

Managing food supplies, managing water resources. Manage the use of medicines for shrimp diseases and use the right techniques.

Managing water supply, quarantine seed before roaming

Selection of varieties, protection of varieties and rearing ponds must be next to the rearing ponds. 


\begin{tabular}{|c|c|c|}
\hline 9 & Irrigation work has not met with aquaculture. & $\begin{array}{l}\text { Developing irrigation and urgent work for } \\
\text { aquaculture. Irrigation systems for aquaculture require } \\
\text { a larger scale to meet the tasks: Water supply and } \\
\text { drainage for aquaculture areas, just doing the work to } \\
\text { prevent salinity, keep fresh, prevent floods and } \\
\text { alum. At the same time, it contributes and rural } \\
\text { transport network. }\end{array}$ \\
\hline 10 & $\begin{array}{l}\text { It is necessary to follow the low water exchange } \\
\text { regime to avoid risks for shrimp. }\end{array}$ & $\begin{array}{l}\text { Open model: Change the water according to the tide, } \\
\text { the release of pond water according to the tidal } \\
\text { difference, usually in the low tide and middle tide, this } \\
\text { type is popular in the extensive farming model. } \\
\text { Closed model: No water exchange, very difficult to } \\
\text { control water quality, usually applied to small ponds } \\
\text { and low salinity areas } \\
\text { Semi-closed model: Circulating water, control water } \\
\text { when changing, water is treated and then cleaned for } \\
\text { ponds. This method requires } 30 \% \text { of the pond } \\
\text { sedimentation compared to the pond. }\end{array}$ \\
\hline
\end{tabular}

\section{Conclusion}

Development of water resources for Litopenaeus vannamei prawn farming is a measure to enhance the ability of exploiting and using water resources sustainably and raising the value of water resources. Bac Lieu is affected by salinity both from the East Sea and the West Sea. Especially in the dry season, tides strongly affect the inland river/canal system, leading to saltwater intrusion both on the river and in the field. The study area is eligible to use tides in exchanging, using, and solving water supply issues for Litopenaeus vannamei prawn farming development.

Sustainable development for Litopenaeus vannamei prawn farming requires resources to be used appropriately and effectively with smart and smart methods so that resources are not degraded and can be used for long term. Sustainable development is an ever-changing goal, a broad vision that humanity today has towards and to realize must go through a long process. This study analyzed and evaluated unsustainable factors of the water quality environment in the study area for the demand for Litopenaeus vannamei prawn farming and determined the level of pollution, the main type of pollution in the water environment in Bac Lieu Litopenaeus vannamei prawn farming area.

The application of water component problem assessed water resources and indicated the limit of Litopenaeus vannamei prawn farming area. The development of some empirical relationships among water quality environmental factors which is possible to identify difficult-to-measure environmental factors through easy-to-measure factors and a tool to quickly assess water quality environmental pollution. This investigation proposed the sustainable development indicators of Bac Lieu coastal Litopenaeus vannamei prawn farming, including the conversion of feed conversion ratio for the cultured shrimp to quantify the homemade food to limit environmental pollution. water for shrimp farming. Proposing solutions for sustainable development of Litopenaeus vannamei prawn farming in Bac Lieu province, especially, irrigation solutions. 


\section{References}

1. Nguyen, N.A., 2011. Master plan on irrigation in the Mekong Delta in the context of climate change - sea level rise. Southern Institute of Water Resources Planning, Ho Chi Minh City.

2. Boy, C.E., 1998. Water quality for pond Aquaculture. Department of Fisheries and Allied Aquaculture Auburn University, Alabama 36849 USA.

3. ARDB, 2018. Statistical report on aquaculture situation in December 2018.
4. Tran, V.M., 2009. A guide to raising vannamei shrimp (Pennaeus vannamei).

5. Nguyen, A.N., 2003. Studying environmental changes due to the implementation of socio-economic development planning. Proposing solutions to the Mekong Delta. State-level science and technology project 07.03 - Southern Institute of Water Resources Research.

6. Huynh, P., 2019. Sustainable development of water resources of Pennaeus vannamei prawn faming in Mekong Delta. 